\title{
Conservative Approach to Unilateral Condylar Fracture in a Growing Patient: A 2.5-Year Follow Up
}

\author{
Elif Bahar Tuna $^{1}{ }^{*}$, Aysun Dündar $^{1}$, Abdülkadir Burak Çankaya $^{2}$ and Koray Gençay ${ }^{1}$ \\ ${ }^{I}$ Department of Pedodontics, Istanbul University Faculty of Dentistry, Istanbul, Turkey \\ ${ }^{2}$ Department of Oral and Maxilofacial Surgery, Istanbul University Faculty of Dentistry, Istanbul, Turkey
}

\begin{abstract}
Condylar fractures in children are especially important because of the risk of a mandibular growth-center being affected in the condylar head, which can lead to growth retardation and facial asymmetry. The purpose of this article is to follow up the two and half year clinical and radiological evaluation of the conservative treatment of a 10 year-old patient, who had a unilateral green-stick type fracture. The patient presented with painful facial swelling localized over the left condylar region, limited mouth-opening and mandibular deviation to the left. Panoramic radiography and computed tomography confirmed the diagnosis of incomplete fracture on the left condyle with one side of the bone fractured and the other bent. Closed reduction was chosen to allow for initial fibrous union of the fracture segments and remodeling with a normal functional stimulus. A non-rigid mandibular splint was applied in order to remove the direct pressure on the fracture side of the mandible. Clinical and radiologic examination after 30 months revealed uneventful healing with reduction of the condylar head and remodeling of the condylar process following conservative treatment.
\end{abstract}

Keywords: Condylar fracture, trauma, growing child, closed management.

\section{INTRODUCTION}

It is well documented that mandibular fracture is the commonest craniofacial injury $[1,2]$ and $19-52 \%$ of them involve the condyle [3]. The anatomical level of the condylar fracture is divided into three sites: the condylar head (intracapsular), the condylar neck (extracapsular) and the subcondylar region [4]. Although the condyle is well protected in the glenoid fossa, its neck is a relatively fragile area [5]. The subcondylar fracture, which was associated with a greenstick fracture, is usually seen at the age of less than 6 years due to the fact that a child's bone is more flexible, so that it can be more likely bent rather than a complete breakage [4].

The etiology of condylar fractures cited includes motor vehicle accidents, falls, work-related fractures, and fractures caused by sporting activities, and personal violence. The most common causes of trauma in children are falls from bicycle, on steps and sports. Most fractures are caused by indirect forces transmitted to the condyle from a blow elsewhere while others result from direct trauma [2]. Trauma are extrinsic factors that can cause severe growth disturbances [6].

Condylar fractures must be focused not only as a cause of direct damage to osseous structures, but also of future disturbances of dentofacial development. Condylar fractures in children are especially important due to the risk of a mandibular growth-center in the cartilage of the condylar

*Address correspondence to this author at the Istanbul University Faculty of Dentistry Department of Pedodontics 34093, Capa, Istanbul, Turkey; Tel: +90 212414 2020; Fax: +90 212531 0515;

E-mail: ebtuna@istanbul.edu.tr head. It can also retard growth and/or cause facial asymmetry $[2,7,8]$. Other complications of the condylar fracture should include pain, restricted mandibular movement, muscle spasm and deviation $[3,8]$.

Some studies demonstrated that, after fracture of the mandibular condyle in children, there is an excellent chance that the condylar process would regenerate to approximately its original size and a small chance that it would overgrow after the injury if an adequate function can be obtained [4, $6]$. It was reported that the presence of the articular disc and capsule seems to play an important role in this process $[2,6]$.

The present case report aims to present the consequences of a conservative approach to condylar fractures in a growing child.

\section{CASE REPORT}

\section{Diagnosis}

A 10-year-old boy attended with his left condyle fractured, caused by a soccer accident. The patient was diagnosed with painful facial swelling localized over the left condylar region, and lateral deviation of the mandible to the left side resulting in a facial asymmetry. His medical history was found to be non-significant. Intraoral examination revealed an anterior crossbite and excessive crowding. Limited mouth opening and mandibular deviation during opening and closure were observed, and mastication and speech were both affected. The clinical diagnosis was supported by panoramic radiography and 3D computed tomography (CT) views. Panoramic radiograph and $\mathrm{CT}$ views confirmed the green-stick (incomplete) fracture on the left condyle in which one side of the bone was fractured and the other was bent (Fig. 1a-b). 

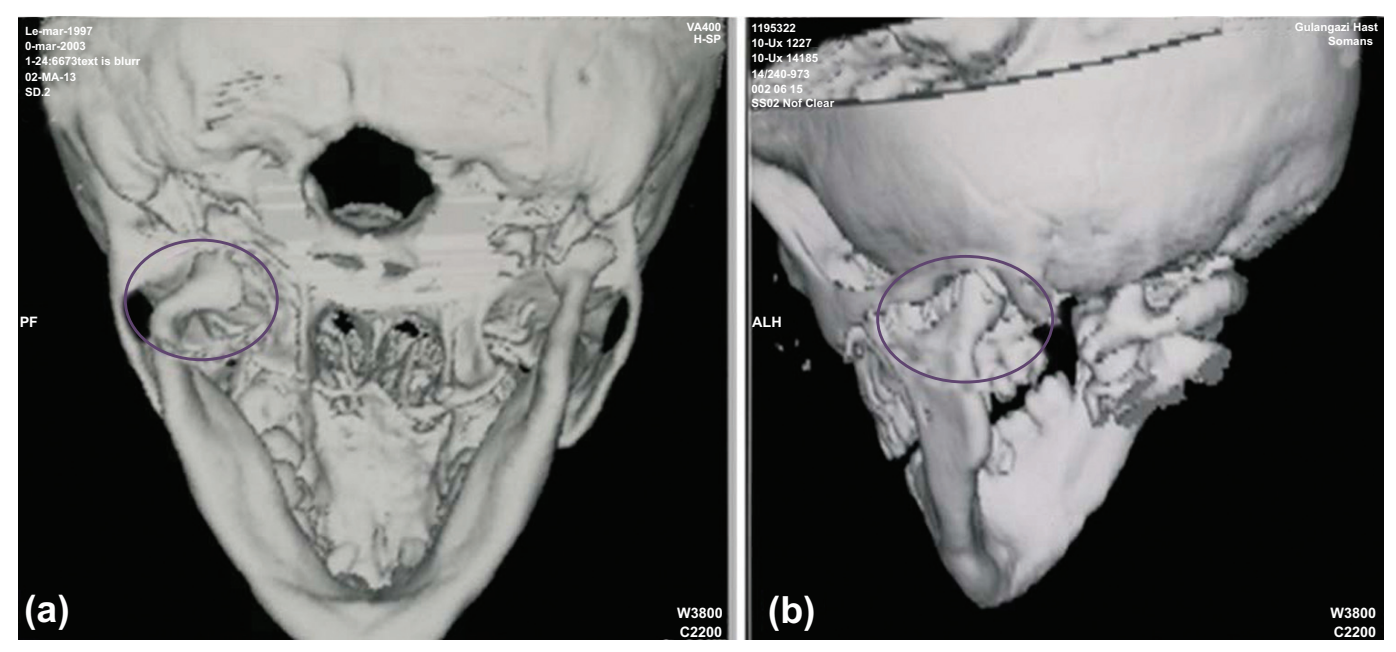

Fig. (1a-b). CT views show condylar fracture at the left mandibular condyle.

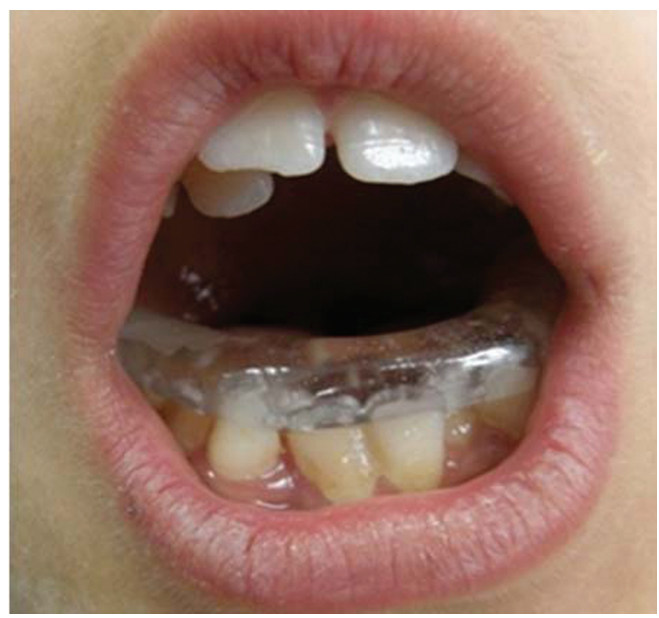

Fig. (2). Intraoral view of non-rigid mandibular splint.

\section{Treatment}

Closed reduction was chosen as a treatment method to allow to initial fibrous union of the fracture segments and obtain remodeling with normal functional stimulus. Alginate impressions of both jaws were taken and stone working models poured. A $3 \mathrm{~mm}$ thick removable acrylic mandibular splint was made by our laboratory technician. Then, a nonrigid mandibular splint was applied in order to remove the direct pressure on the fracture side (left) of the mandible for one month with functional repositioning of the mandible (Fig. 2). Soft diet and rest were suggested. Instructions were given to his parents as for the cleaning of the mandibular splint with a soft toothbrush.

Clinical and radiologic examination at 1, 3, 6, 12 and 27 months revealed uneventful healing with reduction of the condylar head and remodeling of the condylar process following conservative treatment (Fig. 3a-d). During these follow-up periods, it was observed that the patient was cooperative and used his splint in a proper way. At 1, 3, 6, 12 and 30-month CT follow-ups, neither deviation nor pain was observed. It was also observed that the patient's occlusion was normal and mouth opening was within normal limits. After initial treatment, reduction of the condylar head in the fossa, correct positioning of the ramus (repositioning) and
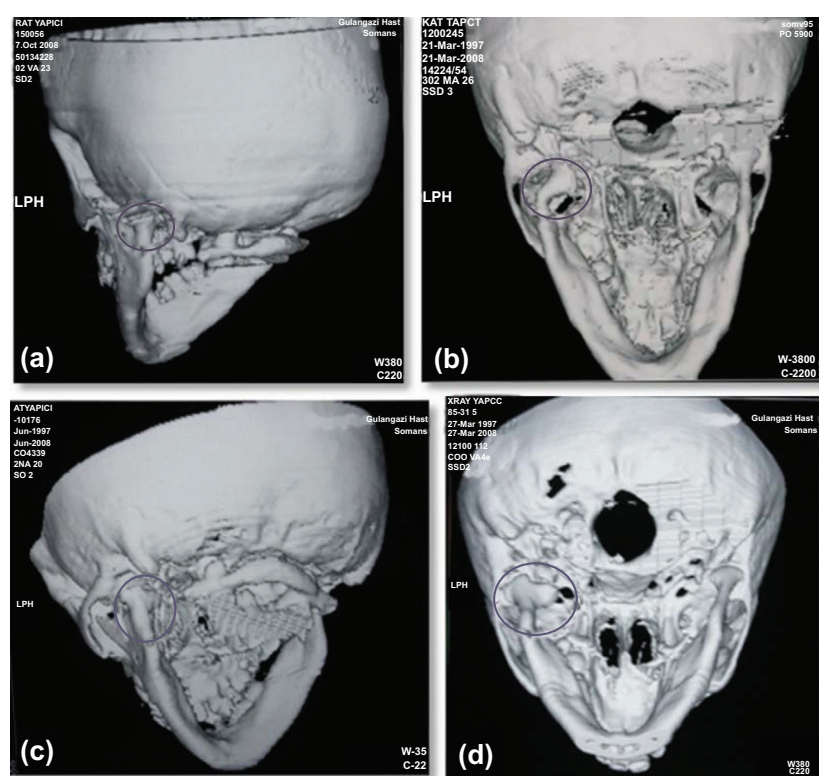

Fig. (3a-d). 1 month, 3 months, 6 months and 12 months control CT views.

new bone modeling (i.e., remodeling) of the submandibular condyle observed by CT scan resulted. Bone callus was observed on the anterior surface of the condyle, and the condylar axis was flattened. TMJ disorders such as ankylosis and dysfunction, or malocclusion as well as the limitation of the mouth opening were not observed after 30 months (Fig. 4ab). It was noticed that the patient has a Class I occlusion with anterior crowding. However, since orthodontic tooth movement may precipitate dysfunctional symptoms, orthodontic teeth alignment was postponed until complete healing had occurred.

\section{DISCUSSION}

Treatment of condylar fractures depends on various factors; (i) the age of the patient, (ii) the co-existence of other mandibular or maxillary fractures, (iii) whether the condylar fracture is unilateral or bilateral, (iv) the level and displacement of the fracture, and (v) the state of the dentition and the dental occlusion $[2,7]$. 

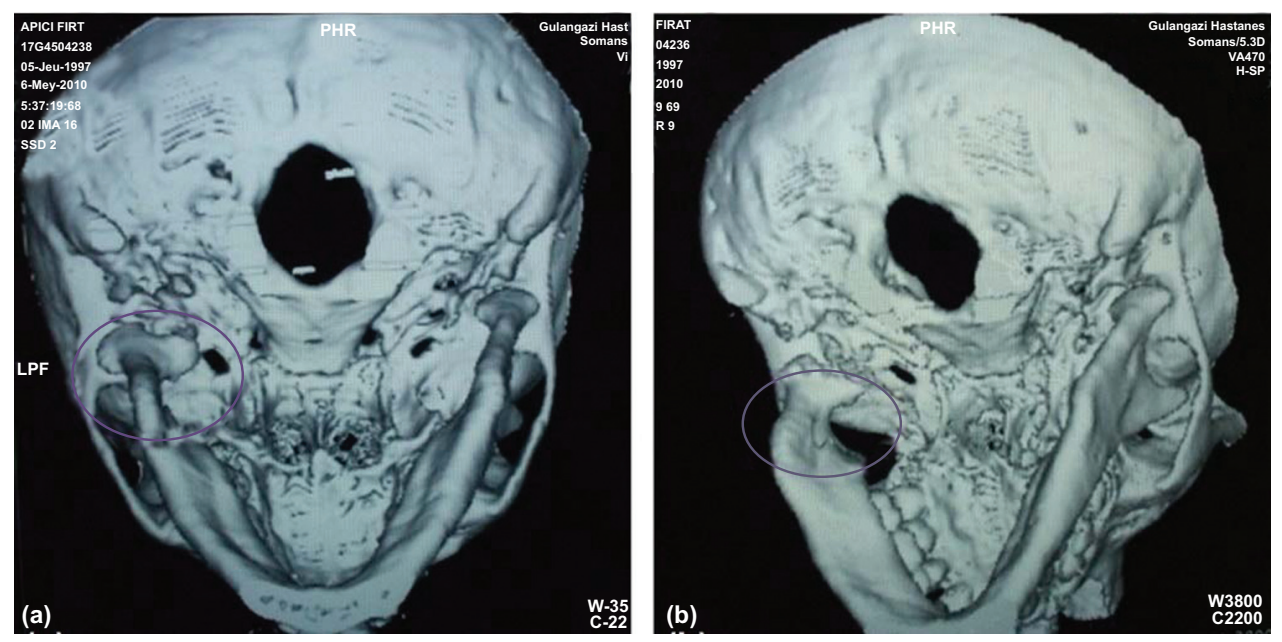

Fig. (4a-b). Follow up CT views after 30 months.

Condylar fractures may give rise to serious problems, such as growth disturbances of the face, disorders of the TMJ (such as ankylosis and dysfunction), malocclusion, and chronic dislocation and pain on the injured side $[1,2,7]$. Following trauma there may be an asymmetry at multiple facial levels, including both jaws and varying degree of limited mandibular movement due to muscle spasm, edema and haemarthrosis. The management of mandibular condylar fractures in children has been aimed at restoring normal joint function, occlusion and symmetry [2,7].

There are two main therapeutic approaches for condylar fractures: (i) conservative treatment with intermaxillary mobilization followed by functional therapy; and (ii) surgical intervention to reposition and stabilize the fragments. Functional therapy is generally preferred in childhood, since it permits early mobilization, adequate functional stimulation of condylar growth in growing subjects and bone remodeling in all subjects $[3,5,9]$. It is indicated in almost all condylar fractures occured in childhood, and in intracapsular and extracapsular fractures that do not include serious condylar dislocation in adults [7, 9]. On the other hand, condylar fractures are surgically treated in the case of displaced fractures or dislocation of the condylar head especially in adults [2,9]. Different techniques are described as a treatment alternative such as open reduction with intraosseous fixation, immobilization with intermaxillary fixation (IMF) or nonimmobilization and early mobility [9]. Open reduction and internal fixation may be indicated in bilateral injuries with loss of a vertical ramus height. However, where the condyle is minimally displaced and the height of the ramus is normal, the closed treatment is appropriate [10]. The correct determination of the treatment depends on various influencing factors, including (i) the physical and imaging evidence of the fracture, (ii) the extent of injury (whether it is unilateral or bilateral), (iii) the level of the fracture, the degree of displacement and dislocation, (iv) the size and position of the fractured condylar segment, (v) the dental malocclusion and mandibular dysfunction, and (vi) the completeness of the dentition and the age of the patient. However, there is a great consensus that closed management is advocated for such fractures $[2,8,11]$.

Children have a greater osteogenic potential than adults which allows rapid union within three weeks and non-union

or fibrous union is rarely seen in pediatric patients. These factors allow for a much greater potential to remodel even in imperfectly reduced fractures [4]. The usually favorable prognosis of a pediatric condylar fracture not only means the normal union of fractured fragments but also morphologic structure recovery of the condyle without any growth disturbances [11]. In the presented case, we considered that conservative treatment of condylar fracture in growing child resulted in a good functional result with reduction of the condylar head in the fossa and correct positioning of the ramus.

We concluded that a conservative treatment method is technically simpler with a satisfactory long-term outcome of jaw function in the management of mandibular condylar fractures in children. At the end of the 30 months follow-up period, our case demonstrated that a condylar fracture during the growing period in children is compensated for by continuous condylar growth and remodeling.

Experimental and clinical studies have shown the great potential for compensation and remodeling of the condyle [4, 7]. Li et al. used Wistar rats to investigate the mechanism in favorable healing of pediatric condylar fractures. After the entire healing process was investigated, the authors concluded that the growth potential and remodeling capability of a condyle during its growing period might be the intrinsic factor for the favorable prognosis of condyle fracture managed by closed procedures [11]. Histomorphometric studies found that during active growth, trabecular bone remodeling with successive enchondral ossification occurs in the healing of condylar fractures [7]. It appears that pediatric condylar fractures could be managed by closed procedures and obtain an encouraging prognosis, as long as there was no damage to the fibrous attachments of the capsule, disc, and condylar cartilage [11].

\section{CONCLUSION}

In conclusion, a non-surgical functional approach in children presenting unilateral fractures of the mandibular condyle prevents distortion in subsequent growth. We hypothesize that the proliferation in the chondrocyte layer supports new bone formation in the fractured condyle, which contributes to the continuous and simultaneous condylar growth in the healing process of fractures during the growing period. 
The results obtained in this case demonstrate that functional therapy resulted in remodeling with functional adaptation of the condyle to the fossa.

\section{REFERENCES}

[1] Silvennoinen U, Lindqvist C, Oikarinen K. Dental injuries in association with mandibular condyle fracture. Endod Dent Traumatol 1993; 9: 254-9.

[2] Zachariades N, Mezitis M, Mourouzis C, Papadakis D, Spanou A. Fractures of the mandibular condyle: a review of 466 cases. Literature review, reflections on treatment and proposals. J Craniomaxillofac Surg 2006; 34: 421-32.

[3] Valiati R, Ibrahim D, Abreu ME, et al. The treatment of condylar fractures: to open or not to open? A critical review of this controversy. Int J Med Sci 2008; 5: 313-8.

[4] Kalia V, Singh AP. Greenstick fracture of the mandible: A case report. J Indian Soc Pedod Prev Dent 2008; 26: 32-5.

[5] Proffit WR. Contemporary orthodontics. $2^{\text {nd }}$ ed. St Louis: Mosby, Mosby Year Book 1993.
[6] Gianni` E, Bruno E, Farronato G, Giannı AB. The temporomandibular joint: diagnosis-functional aspects. Front Oral Physiol 1990; 7: 38-45.

[7] Farronato G, Grillo ME, Giannini L, et al. Long-term results of early condylar fracture correction: case report. Dent Traumatol 2009; 25: e37-42.

[8] Hackett JF, Sleeman DJ. Vertical-split fracture of mandibular condyle and its sequelae. Br Dent J 2001; 191: 557-8.

[9] De Riu G, Gamba U, Anghinoni M, Sesenna E. A comparison of open and closed treatment of condylar fractures: a change in philosophy. Int J Oral Maxillofac Surg 2001; 30: 384-9.

[10] Lloyd T, Nightingale C, Edler R. The use of vacuum-formed splints for temporary intermaxillary fixation in the management of unilateral condylar fractures. Br J Oral Maxillofac Surg 2001; 39: 301-3.

[11] Li Z, Zhang W, Li ZB, Li JR. Mechanism in favorable prognosis of pediatric condylar fractures managed by closed procedures: an experimental study in growing rats. Dent Traumatol 2010; 26(3): 22835 .

(C) Tuna et al.; Licensee Bentham Open.

This is an open access article licensed under the terms of the Creative Commons Attribution Non-Commercial License (http://creativecommons.org/licenses/by-nc/3.0/) which permits unrestricted, non-commercial use, distribution and reproduction in any medium, provided the work is properly cited. 